\title{
High Temperature Deformation of TC18 Titanium Alloy
}

\author{
Li Chenwei ${ }^{1}$, Xie Hui ${ }^{2}$ Mao Xiaonan ${ }^{3}$, Zhang Pengsheng ${ }^{3}$, Hou Zhimin ${ }^{3}$
}

${ }^{1}$ Xi'an University of Technology, Xi'an 710048, China; ${ }^{2}$ Xi'an Aeronautical University, Xi'an 710089, China; ${ }^{3}$ Northwest Institute for Nonferrous Metal Research, Xi'an 710016, China

\begin{abstract}
Hot deformation behavior of as-cast TC18 titanium alloy has been investigated by the Gleeble-3800 simulator in the temperature range $1000 \sim 1150{ }^{\circ} \mathrm{C}$, the strain rate range $0.01 \sim 10 \mathrm{~s}^{-1}$ at the deformation degree of $70 \%$. The deformation activation energy was evaluated, processing maps for hot working were established on the basis of variable efficiency in power dissipation with temperature and strain rate, and interpreted according to the microstructure observation. The optimum processing parameters of hot deformation in the range of this experiment were achieved by different variables of the hot processing map, which can be used as a reference for hot working of as-cast TC18 titanium alloy.
\end{abstract}

Key words: as-cast TC18 titanium alloy; hot deformation; processing maps; microstructure

TC18 alloy (Ti-5 Al-5Mo-5V-1Fe-1Cr) is a kind of near- $\beta$ titanium alloy with high strength and high alloying. In particular it has the highest strength among the titanium alloys after annealing. TC18 titanium alloy has the biggest hardenability of cross-section size $(250 \mathrm{~mm})$, which is higher than the other same strength titanium alloys, such as Ti-1023 and Ti-17 ${ }^{[1]}$. Therefore, TC18 has been widely used as large load-bearing structure in the aerospace industry.

It is believed that microstructure of titanium alloys is extremely sensitive to processing parameters and heat treatments. Microstructural control by proper forging process is one of the key means to enhance the performance of titanium alloy forging. However, most of the forging processes of titanium alloy, especially the subtransus cogging process, are based on empiric with few scientific factors. Therefore, it causes the waste of manpower, material resources and extends the production cycle. Meanwhile, the quality of forging is difficult to assure, like the risk of defects such as cracking and holes ${ }^{[2]}$.

In the last decade, high temperature compression deformation and processing map based on the dynamic material model (DMM) have been proved to be useful ways for revealing deformation characteristics and optimizing the hot working processes of titanium alloys ${ }^{[3]}$. For TC18 titanium alloy, most studies are focusing on the as-forged one. Sha et al. ${ }^{[4,5]}$ investigated the deformation mechanism of TC18 and the effect of different deformation conditions on deformation resistance and microstructure. Seshacharyulu et al. $^{[6]}$ studied the hot deformation mechanism in Ti-6Al-4V alloy and associated the thermal activation constitutive model with the processing map to analyze the globularization of the Widmanstatten microstructure. Chen et al. ${ }^{[7]}$ established the processing map of TC18 alloy based on true flow stress-true strain curves and found out that the stress-strain curves have significantly softened characteristics at the two-phase region temperature, but under the temperature in the single-phase region and at high strain rates, the alloy shows a discontinuous yielding phenomenon.

In the present study, the high temperature deformation behaviors of as-cast TC18 titanium alloy were investigated through the isothermal compression experiment. The effect of the processing parameters on the flow stress of as-cast TC18 alloy was investigated, and the apparent activation energy for deformation was calculated at different deformation conditions. In addition, the processing maps of isothermally compressed as-cast TC18 alloy at the strains of $0.2,0.4,0.6$ and 0.8 were constructed.

$\overline{\text { Received date: February 06, }}, 2016$

Foundation item: Science and Technology Innovation Team Key Plan of Shaanxi Province "Titanium Alloy Research and Innovation Team" (2012KCT-23)

Corresponding author: Li Chenwei, Master, Xi'an University of Technology, Xi'an 710048, P. R. China, E-mail: lichenwei825@163.com 


\section{Experiment}

The studied material was as-cast TC18 titanium alloy ingot produced by Northwest Institute for Nonferrous Metal Research. Its chemical compositions (wt\%) is as follows: $\mathrm{Al}$ 5.95, Mo 4.95, V 4.87, Cr 2.95, Fe 1.61, and Ti bal. The $\alpha / \beta$ transus temperature of this titanium alloy has been measured as $894{ }^{\circ} \mathrm{C}$ by the differential thermal analysis.

The macrograph of the TC18 titanium alloy ingot is shown in Fig.1a. In order to ensure the representation and consistency of the compressed specimens, small cylinders with a dimension of $\Phi 12 \mathrm{~mm} \times 17 \mathrm{~mm}$ were cut out from the ingot as shown in Fig.1b, and then machined into thermal simulated compression specimens with $\Phi 10 \mathrm{~mm} \times 15 \mathrm{~mm}$.

The original structure of the material is shown in Fig.2, a basketweave structure consisting of equiaxed $\beta$ grains with a size of $1 \sim 2 \mathrm{~mm}$ and acicular $\alpha$ precipitates inside it. Hot compression experiment was performed on Gleeble-3800 thermo-mechanical simulator, within the deformation temperature range $1000 \sim 1150{ }^{\circ} \mathrm{C}$ at $50{ }^{\circ} \mathrm{C}$ intervals, strain rate range $0.01 \sim 10 \mathrm{~s}^{-1}$ at order magnitude intervals, and the deformation degree was $70 \%$. The specimens were heated at $10{ }^{\circ} \mathrm{C} / \mathrm{s}$ to the designed temperatures in a resistance furnace, and then held for 5 min. In order to get an accurate test temperature, thermocouples were tag welded to the middle of the specimen side faces before the test. After the deformation was completed, the specimen was cooled down to room temperature through gas jet cooling. Then the deformed specimen was divided by wire cutting along the compression axis. The specimens were ground, polished, and etched using the solution of hydrofluoric acid: nitric acid: lactic acid of $1: 3: 5$, and their microstructures were observed through OLMPUS PMG optical microscope.

\section{Results and Discussion}

\subsection{Flow stress-strain curve}

The true stress-true strain curves in Fig. 3 show that as all temperature ranges chosen for the test are in the $\beta$

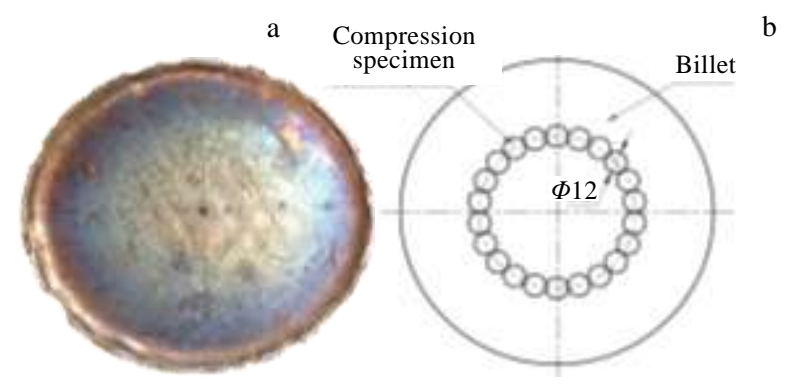

Fig.1 TC18 titanium alloy billet (a) and sampling (b)

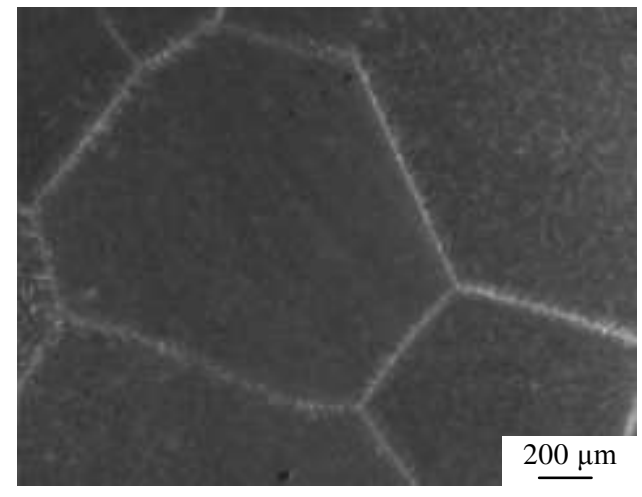

Fig.2 Original microstructure of as-cast TC18

single-phase region, the curves for the same temperature versus different strain rates exhibit the similar characteristics, i.e. the flow stress increases as the degree of deformation increases, and tends to level out or go down slightly after reaching a summit, which indicates that the work-hardening and flow softening reach a dynamic equilibrium, reflecting the dynamic recovery characteristics. Under the same strain rate, as the deformation temperature rises, the peak stress and the steady-state flow stress decreases, while the deformation temperature is certain, the steady-state flow stress increases with the increased strain rate. It indicates that under the test conditions, the alloy has positive strain rate sensitivity, i.e. it is difficult for the alloy to reach the steady-state rheological under the conditions of relatively high strain rate and low temperature.

When the strain rate is $0.1 \mathrm{~s}^{-1}$, the true stress-true strain curve exhibits an obvious stress oscillation and then gradually levels out. It indicates that recrystallization of $\beta$ phase, spheroidization or cracking of $\alpha$ lamella could have occurred within the material structure. Under the conditions of this test, the great majority of the material structure is $\beta$ phase. Therefore the possibility of $\alpha$ lamella spheroidization is excluded. In addition, according to observations of the deformation microstructure, there are no defects like cracks, but only a small amount of recrystallized structure exist. Therefore, the oscillation in the true stress-true strain curve is a result of $\beta$ phase recrystallization. At low strain rate, the recrystallized grains have sufficient time for nucleation and growth; however at different temperatures, the critical deformation required for nucleation of the recrystallized grains is different, so the curves show different oscillation peak positions and widths. When the strain rate is $10 \mathrm{~s}^{-1}$, the flow stress shakes in varying degrees with the increase of the strain, due to stress concentration and stress relaxation at the grain boundaries and within the grains, representing a discontinuous yielding phenomenon ${ }^{[8,9]}$. 

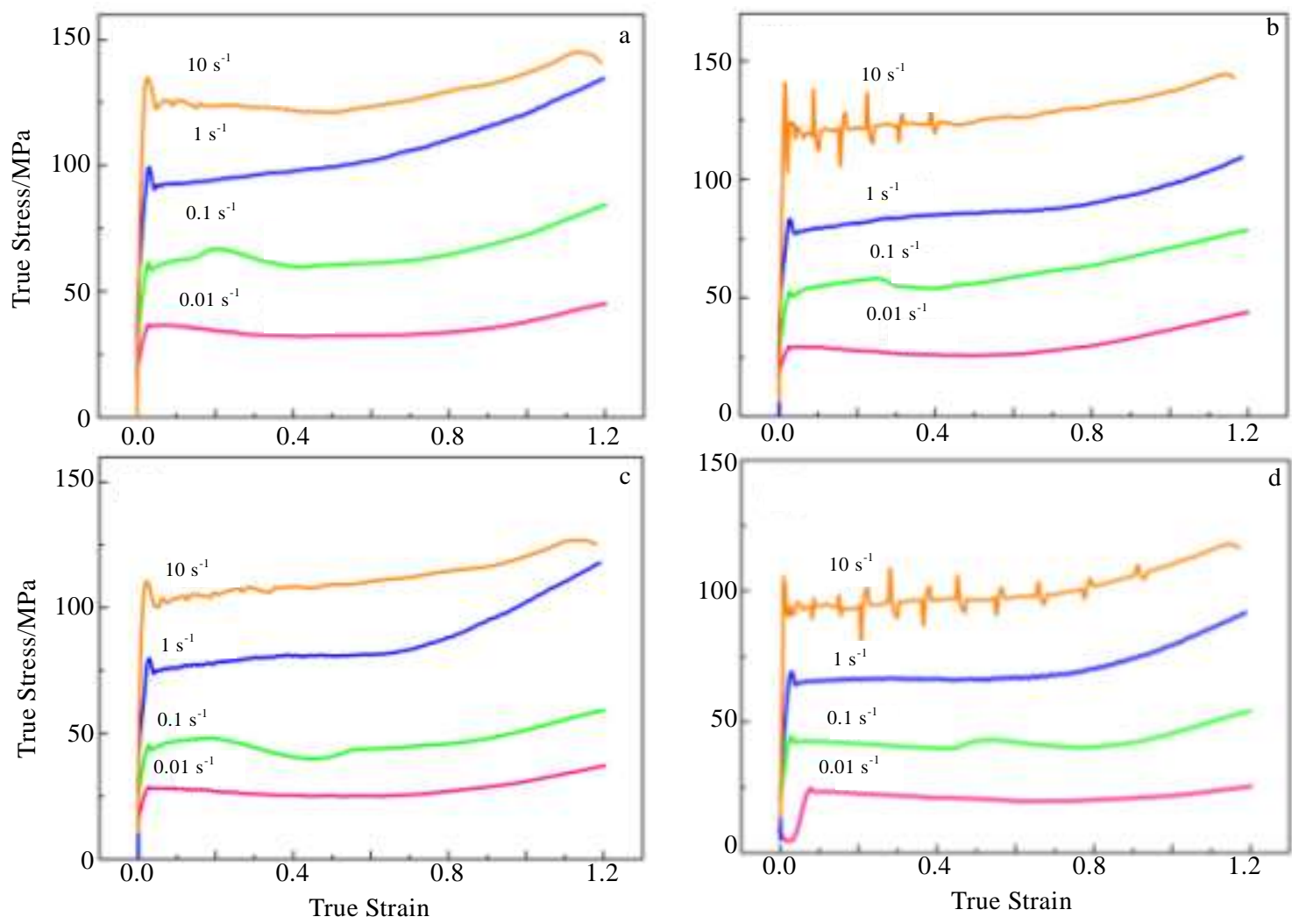

Fig.3 True stress-true strain curves of as-cast TC18 titanium alloy compressed under different deformation conditions: (a) $1000{ }^{\circ} \mathrm{C}$, (b) $1050{ }^{\circ} \mathrm{C}$, (c) $1100{ }^{\circ} \mathrm{C}$, and (d) $1150{ }^{\circ} \mathrm{C}$

Furthermore, the true stress-true strain curve in Fig. 3 has an upward trend under the large strain condition, possibly because the contact area between the deforming specimen and the die gradually increases with the increase of the deformation, and the friction at the contact surface increases with the consumption of the lubricant. Thus the deformation resistance increases during the specimen compression process, eventually leading to increase of the flow stress.

\subsection{Apparent activation energy for deformation}

The metal deformation at high temperature is a thermal activation process controlled by thermodynamic parameters. The comprehensive influence of temperature and strain rate on flow stress is usually analyzed using a kinetic equation controlled by thermal activation. The deformation activation energy of as-cast TC18 titanium alloy was calculated using the hyperbolic-sine type kinetic equation proposed by Sellars and Tegart ${ }^{[10]}$ :

$$
\dot{\varepsilon}=A \sinh (\alpha \sigma)^{n} \exp (-Q / R T)
$$

where $A, \alpha$ are material constants, $\dot{\varepsilon}$ is strain rate $\left(\mathrm{s}^{-1}\right), \sigma$ is flow stress (MPa), $T$ is absolute temperature $(\mathrm{K}), Z$ is stress exponent, $Q$ is deformation activation energy $\left(\mathrm{kJ} \cdot \mathrm{mol}^{-1}\right)$, and $R$ is gas constant $(R=8.314 \mathrm{~J} / \mathrm{mol} \cdot \mathrm{K})$. From Eq.(1) the equation for deformation activation energy $Q$ can be derived, as follows:

$$
Q=R\left[\frac{\partial \ln \sinh (\alpha \sigma)}{\partial(1 / T)}\right] \cdot\left[\frac{\partial \ln \dot{\varepsilon}}{\partial \ln \sinh (\alpha \sigma)}\right]
$$

According to the experimental results of the isothermally compressed as-cast TC18 titanium alloy, the apparent activation energy in $\beta$ phase region of the test is calculated to be $187.25 \mathrm{~kJ} / \mathrm{mol}$ through Eq.(2). It is close to and slightly higher than $153 \mathrm{~kJ} / \mathrm{mol}$, that is the activation energy of self-diffusion in the $\beta$ phase obtained by some scholars $^{[11]}$. It indicates that its deformation mechanism is mainly dynamic recovery, with a certain dynamic recrystallization phenomenon, which is in line with the varying pattern of the stress-strain curve. However, the transformation mechanism cannot be accurately analyzed only using the flow curve and the activation energy; therefore further analysis is needed on combining the processing map and the deformed structure.

\subsection{Processing map}

\subsubsection{Processing map based on Murty criterion}

The theory of dynamic material model was put forward first by Prasad et $\mathrm{al}^{[12]}$. The theoretical basis is severe plastic flow continuum mechanics, physical system model, and irreversible thermodynamics ${ }^{[13]}$. According to dynamic material model theory, the instantaneous power $P$ absorbed 
by the work-piece from the equipment and die is dissipated through two ways: the power consumption caused by plastic deformation is called dissipator content $G$, most of which converts to viscoplastic heat; and the power consumption caused by structural change during material deformation is called dissipator co-content $J$. Then the power $P$ can be written as follows:

$$
P=\overline{\sigma \bar{\varepsilon}}=G+J=\int_{0}^{\dot{\varepsilon}} \bar{\sigma} \mathrm{d} \dot{\bar{\varepsilon}}+\int_{0}^{\sigma} \dot{\varepsilon} \mathrm{d} \bar{\sigma}
$$

Where $\dot{\bar{\varepsilon}}$ is the effective strain rate, and $\bar{\sigma}$ is the effective stress. The rate of change of $J$ and $G$ constitutes the equation defining the strain-rate sensitivity of the material $(m)$, as follows:

$$
m=\left[\frac{\partial J}{\partial G}\right]_{\varepsilon, T}=\left[\frac{\partial(\ln \bar{\sigma})}{\partial(\ln \dot{\bar{\varepsilon}})}\right]_{\varepsilon, T}
$$

Where $\varepsilon$ is the equivalent strain and $T$ is the deformation temperature. During the process of material heating, for an ideal linear dissipation $(m=1)$, at this moment $J$ is at its maximum $\left(J_{\max }=P / 2\right) . J / J_{\max }$ is defined as efficiency of dissipation expressed with $\eta$, so:

$$
\eta=\frac{J}{J_{\max }}=\frac{2 J}{P}=2\left(\frac{P-G}{P}\right)=2\left(1-\frac{G}{P}\right)=2\left(1-\frac{1}{\sigma \dot{\varepsilon}} \int \sigma \mathrm{d} \dot{\varepsilon}\right)
$$

The curve of efficiency of dissipation $(\eta)$ changing with the strain rate and temperature constitutes the power dissipation map.

Murty and Spigarelli et al. ${ }^{[14]}$ think that the $m$ value for the pure metals and low-alloying metals can be simply considered to be constant. However it varies with the strain rate for the complicated alloys system. Based on this situation, Murty derived the criteria for instability area suitable for any stress-strain rate curve:

$2 m<\eta$, or $\eta \leq 0$

Or when $0<\eta \leq 2 m$ and $0<m \leq 1$

the material flows stably.

The processing maps of as-cast TC18 titanium alloy were established based on the above equation as shown in Fig.4 ( $\varepsilon=0.2$, $0.4,0.6$, and 0.8). These maps show that the safe area for hot processing varies with the increase of the strain; the shade area is the instability area, while the white area is the safe area.

\subsubsection{Analysis of microstructure}

The processing map can be roughly divided into 5 regions according to the characteristics of $\eta$. They are marked as I-V in the processing map (Fig.4).

Region I: in the temperature range $1000 \sim 1050{ }^{\circ} \mathrm{C}$, and the strain rate range $0.8 \sim 10 \mathrm{~s}^{-1}$, efficiency of dissipation rate $\eta$ is the lowest, less than 0.26 .

Region II: in the temperature range $1050 \sim 1150{ }^{\circ} \mathrm{C}$, and the strain rate range $1 \sim 10 \mathrm{~s}^{-1}$, power dissipating rate is
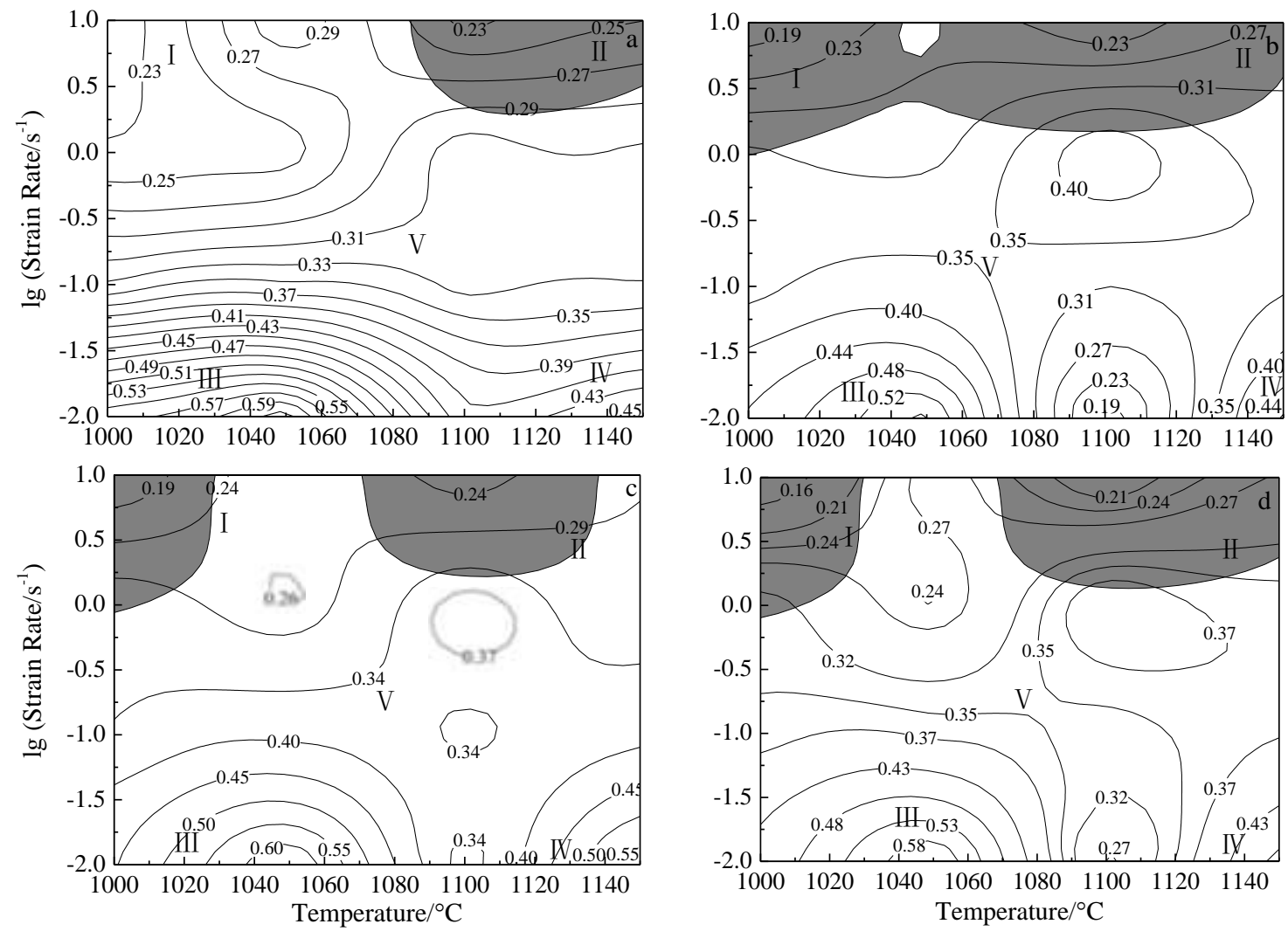

Fig.4 Processing maps of as-cast TC18 titanium at different strains: (a) $\varepsilon=0.2$, (b) $\varepsilon=0.4$, (c) $\varepsilon=0.6$, and (d) $\varepsilon=0.8$ 
slightly greater than that of region but still relatively small (less than 0.32).

Region III: in the temperature range $1000 \sim 1070{ }^{\circ} \mathrm{C}$, and the strain rate range $0.01 \sim 0.05 \mathrm{~s}^{-1}$, the dissipation rate is greater than 0.45 , reaching 0.6 maximum.

Region IV: in the temperature range of $1130 \sim 1150{ }^{\circ} \mathrm{C}$ and the strain rate range $0.01 \sim 0.05 \mathrm{~s}^{-1}$, the dissipation rate is all above 0.45 .

Region V: It is in the middle of the processing map, with the temperature range $1050 \sim 1120^{\circ} \mathrm{C}$, the strain rate $0.1 \sim 1 \mathrm{~s}^{-1}$, and the dissipation rate $\eta$ is between 0.34 and 0.4. From Fig.4, it can be seen that both regions I and II are in the instability area, and the rest is in the safe area of processing.

In the hot compressed specimens at regions I and II we can find shear cracks along the $45^{\circ}$ direction (indicated by the arrow in Fig.5a) and longitudinal cracks (Fig.5b), and local flow characteristics in the deformed microstructure, with the banded structure resulting from local flow (indicated by the arrow in Fig.5c) at certain angle to the compression direction.

During hot compression deformation, the specimen is under axial compressive stress only, but the shear stress at the direction of $45^{\circ}$ to the compressive axis is the biggest; therefore cracking along $45^{\circ}$ happens sometimes. The lower the transformation temperature, and the higher the strain rate, the bigger odd for shearing crack to take place. The direction of longitudinal crack is parallel to the compression axis direction, mainly due to additional tensile stress at the circumferential direction of the specimen under the action of external forces. And local plastic flow produces great local deformation, which could easily evolve into local thermoplastic instability, so shear crack would possible take place. Thus cracks and local plastic flow are the causes of flow instability in regions I and II, and should be avoided during hot processing.

Recrystallized grains are present in both regions III and IV. The grains with zigzag boundaries are typical continuous recrystallization as shown in Fig.6. The higher

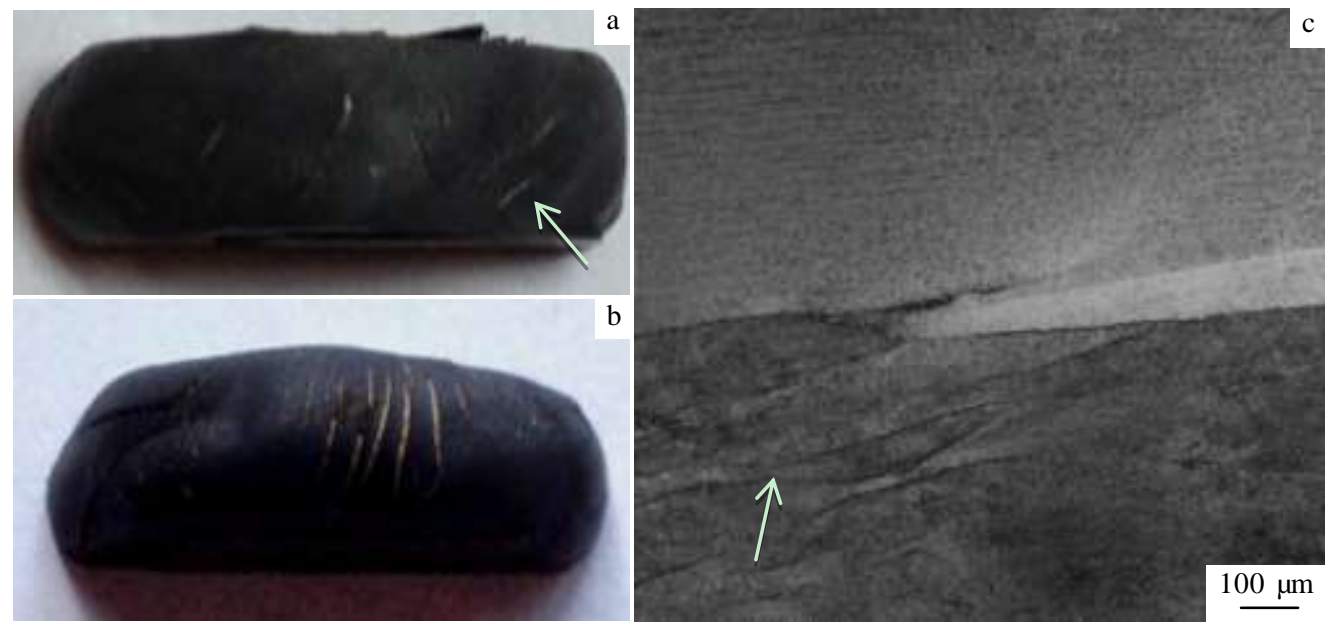

Fig.5 Cracks and local flow of as-cast TC18 titanium alloy during hot compression tests: (a) shear crack occurring at $1000{ }^{\circ} \mathrm{C}, 10 \mathrm{~s}^{-1}$; (b) longitudinal crack occurring at $1150{ }^{\circ} \mathrm{C}, 10 \mathrm{~s}^{-1}$; (c) local flow occurring at $1000{ }^{\circ} \mathrm{C}, 10 \mathrm{~s}^{-1}$
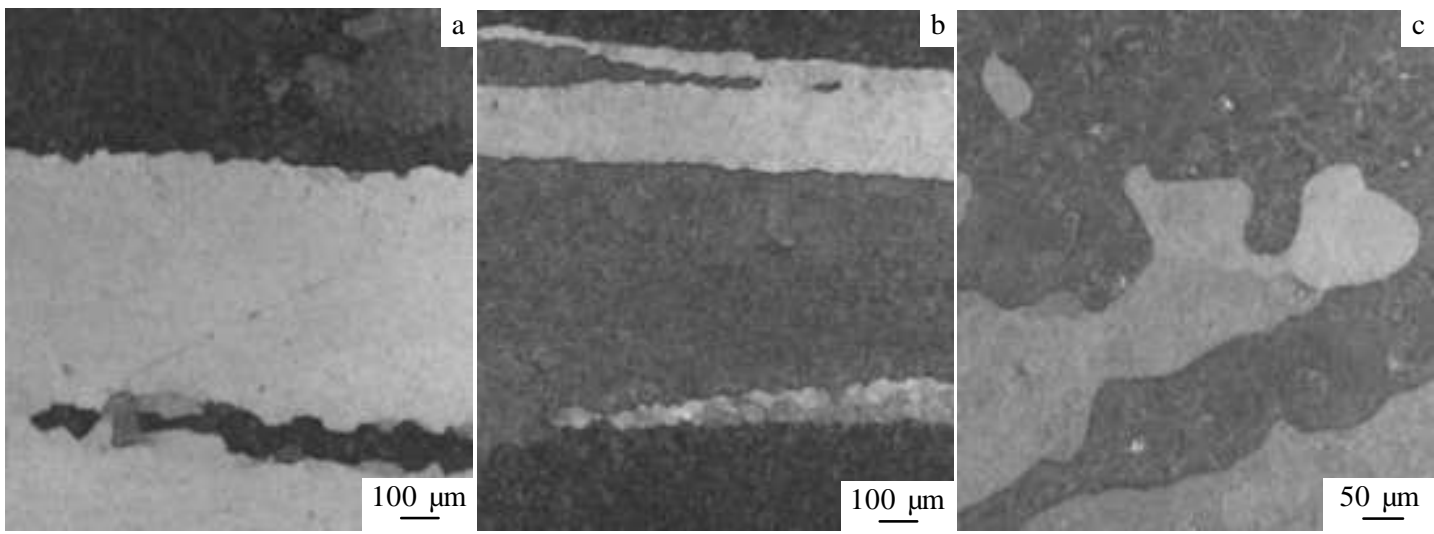

Fig.6 Continuous recrystallization of as-cast TC18 titanium alloy occurred at $1000{ }^{\circ} \mathrm{C}, 0.01 \mathrm{~s}^{-1}$ (a); $1050{ }^{\circ} \mathrm{C}, 0.1 \mathrm{~s}^{-1}(\mathrm{~b}) ; 1150{ }^{\circ} \mathrm{C}$, $0.01 \mathrm{~s}^{-1}(\mathrm{c})$ 
the temperature and the lower the strain rate, the more obvious the continuous recrystallization phenomenon. According to the theories of Prasad ${ }^{[15]}$, for high stacking fault energy alloys, dynamic recovery during deformation is likely to take place through cross-slip or climbing, the dislocation nucleation rate is high, and recrystallization is mainly controlled by mobility of the grain boundaries. For body centered cubic metals, the stronger dynamic recovery at thermal deformation causes lower dislocation density, leaving insufficient driving force for recrystallization nucleation. Therefore in the high temperature recovery stage, there is not any process of nucleation and growth of new grains, but the recovery sub-grains are formed directly. These sub-grains grow through combination, and bear deformation occurs again during the subsequent deformation process, so the grain boundaries are featured by the zigzag shape.

Region V: It is located in the stable area of the processing map, but not in the peak dissipation area. It can be seen from Fig.7 that there is neither cracks nor local flow in the microstructure, which shows that no defects are formed in the deformation of the alloy under such deformation condition. However, there are a small amount of recrystallized grains only at the grain boundaries, and the structure is not very even. Therefore it is not the preferred optimization area at deformation.

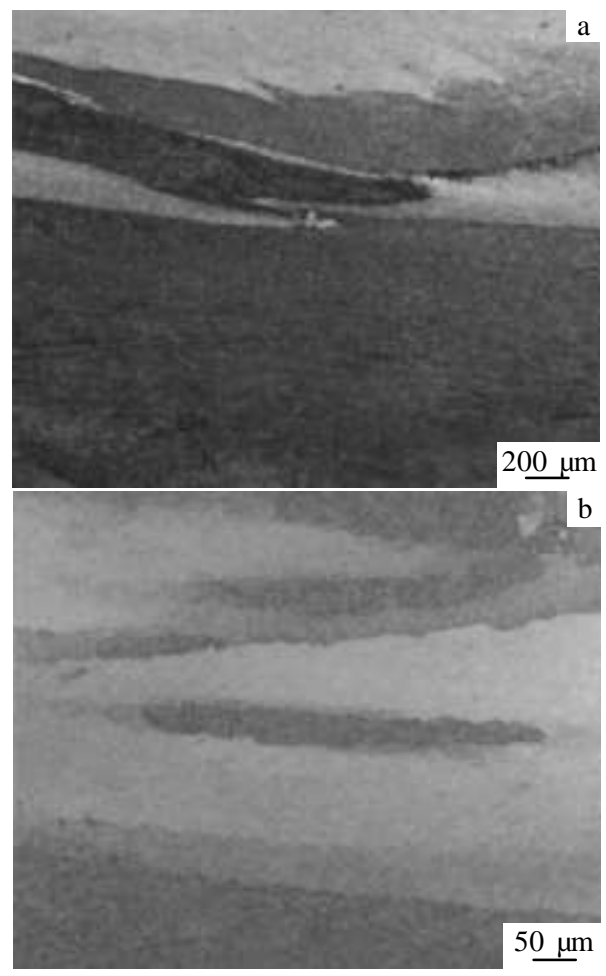

Fig.7 Microstructure of as-cast TC18 titanium alloy occurring at $1050{ }^{\circ} \mathrm{C}, 1 \mathrm{~s}^{-1}$ (a) and $1100{ }^{\circ} \mathrm{C}, 0.1 \mathrm{~s}^{-1}(\mathrm{~b})$

\section{Conclusions}

1) The hot compression deformation in the $\beta$ phase region of as-cast TC18 alloy, its flow stress-strain curves mostly present dynamic recovery characteristics, namely the main deformation mechanism of the as-cast TC18 titanium alloy is dynamic recovery, and flow softening phenomenon takes place under the condition of low temperature and high strain rate.

2) During hot processing of the as-cast TC18 titanium alloy, the instability area is mainly in regions I and II (region I, the temperature range $1000 \sim 1050{ }^{\circ} \mathrm{C}$, the strain rate range $0.8 \sim 10 \mathrm{~s}^{-1}$; region II, the temperature range $1050 \sim 1150{ }^{\circ} \mathrm{C}$, the strain rate range $1 \sim 10 \mathrm{~s}^{-1}$ ), and the rest is the safe area.

3) Cogging of TC18 titanium alloy ingot should be done at regions III and IV (region III, the temperature range $1000 \sim 1070{ }^{\circ} \mathrm{C}$ and the strain rate range $0.01 \sim 0.05 \mathrm{~s}^{-1}$; region IV, the temperature range $1130 \sim 1150{ }^{\circ} \mathrm{C}$ and the strain rate range $0.01 \sim 0.05 \mathrm{~s}^{-1}$ ). For cogging down at the first heat, the best temperature would be $1050{ }^{\circ} \mathrm{C}$ or $1150{ }^{\circ} \mathrm{C}$ to avoid ingot cracking, but the cogging down temperature should then be gradually decreased so as to obtain fine and homogeneous structure.

\section{References}

1 Qu F S, Zhou J, Liu X G et al. Rare Metal Materials and Engineering[J], 2014, 43(1): 120 (in Chinese)

2 Feng F, Zeng W D, Zhu Y C et al. Hot Working Technology[J], 2011, 40(6): 29

3 Prasad Y V P K, Seshacharyulu T. International Materials Reviews[J], 1998, 43: 243

$4 \mathrm{Li} \mathrm{H} \mathrm{E,} \mathrm{Sha} \mathrm{A} \mathrm{X.} \mathrm{Journal} \mathrm{of} \mathrm{Materials} \mathrm{Engineering[J],}$ 2010(1): 85

5 Wang Q R, Sha A X, Huang X. The 14th China Nonferrous Metals Society of Materials Science and Engineering Alloy Processing and Academic Seminar of Corpus[C]. Sanya: The Nonferrous Metals Society of China, 2011 (in Chinese)

6 Seshacharyulu T, Medeiros S C, Morgan J T et al. Scripta Meterialia[J], 1999, 41: 283

7 Chen T Y, Nie X A et al. Hot Working Technology[J], 2012, 41(21): 24

8 Li X. Thesis for Doctorate[D]. Nanjing: Nanjing University of Aeronautics and Astronautics, 2008 (in Chinese)

9 Yu X Q. Thesis for Master Degree[D]. Nanchang: Nanchang Hangkong University, 2009 (in Chinese)

10 Jonas J I, Sellars C M, Teyart W J M. International Materials Reviews[J], 1969, 14(1): 1

11 Bao R Q, Huang X et al. Journal of Materials Engineering [J], 2003, 12: 3

12 Prasad Y V R K, Gegel H L et al. Metallurgy Transaction $A[\mathrm{~J}], 1984,15 \mathrm{~A}(10): 1883$

13 Prasad Y V R K. Metallurgical and Materials Transactions $A[\mathrm{~J}], 1996,27 \mathrm{~A}(1): 235$ 
14 Spigarelli S, Cerri E. Materials Science and Engineering $A[\mathrm{~J}]$, 2002, A327: 145
15 Ravichandran N, Prasad Y V R K. Materials Transactions $[\mathrm{J}]$, 1991, 22A: 2339

\title{
基于热加工图的铸态 TC18 钛合金热变形特征研究
}

\author{
李晨薇 ${ }^{1}$, 谢 辉 $^{2}$, 毛小南 ${ }^{3}$, 张鹏省 ${ }^{3}$, 侯智敏 ${ }^{3}$ \\ (1. 西安理工大学, 陕西 西安 710048) \\ (2. 西安航空学院, 陕西 西安 710089) \\ (3. 西北有色金属研究院, 陕西 西安 710016)
}

\begin{abstract}
摘 要：采用 Gleeble-3800 热模拟机对铸态 TC18 钛合金进行高温热压缩变形实验, 分析该合金在变形温度 $1000 \sim 1150{ }^{\circ} \mathrm{C}$ 、应变速率 $0.01 \sim 10 \mathrm{~s}^{-1}$ 和变形量为 $70 \%$ 条件下流变应力的变化规律。确定 TC18 钛合金热变形激活能, 建立热加工图, 并通过组织观察对热加工图 进行解释。综合不同应变量下的热加工图, 获得了试验参数范围内热变形过程的最佳工艺参数, 为铸态 TC18 钛合金热加工工艺优化 提供理论依据。
\end{abstract}

关键词：铸态 TC18 钛合金; 热模拟压缩; 热加工图; 显微组织

作者简介：李晨薇, 女, 1990 年生, 硕士, 西安理工大学, 陕西 西安 710048, E-mail: lichenwei825@163.com 